\title{
Responses of nectar-feeding birds to floral resources at multiple spatial scales
}

\author{
B. Schmid, H. Nottebrock, K. J. Esler, J. Pagel, A. Pauw, K. Böhning-Gaese, F. M. Schurr and \\ M. Schleuning
}

B. Schmid (baptiste.schmid@vogelwarte.ch), K. Böhning-Gaese and M. Schleuning, Senckenberg Biodiversity and Climate Research Centre (BiK-F) and Senckenberg Gesellschaft für Naturforschung, Senckenberganlage 25, DE-60325 Frankfurt am Main, Germany. KB-G also at: Dept of Biological Sciences, Johann Wolfgang Goethe-Univ., Max-von-Laue-Straße 9, DE-60438 Frankfurt am Main, Germany. - H. Nottebrock, K. J. Esler and BS, Dept of Conservation Biology and Entomology and Centre for Invasion Biology, Stellenbosch Univ., Private Bag X1, Matieland 7602, South Africa. - J. Pagel, F. M. Schurr and HN, Inst. of Landscape and Plant Ecology, Univ. of Hohenheim, August-von-Hartmann-Str. 3, DE-70599 Stuttgart, Germany, and Inst. des Sciences de l'Evolution, UMR 5554, Univ. Montpellier 2, Place Eugène Bataillon, FR-34095 Montpellier Cedex 05, France. - A. Pauw, Dept of Botany and Zoology, Stellenbosch Univ., Private Bag X1, Matieland 7602, South Africa.

\begin{abstract}
The responses of animal pollinators to the spatially heterogeneous distribution of floral resources are important for plant reproduction, especially in species-rich plant communities. We explore how responses of pollinators to floral resources varied across multiple spatial scales and studied the responses of two nectarivorous bird species (Cape sugarbird Promerops cafer, orange-breasted sunbird Anthobaphes violacea) to resource distributions provided by communities of co-flowering Protea species (Proteaceae) in South African fynbos. We used highly resolved maps of about 125000 Protea plants at 27 sites and estimated the seasonal dynamics of standing crop of nectar sugar for each plant to describe the spatiotemporal distribution of floral resources. We recorded avian population sizes and the rates of bird visits to $>1300$ focal plants to assess the responses of nectarivorous birds to floral resources at different spatial scales. The population sizes of the two bird species responded positively to the amount of sugar resources at the site scale. Within sites, the effects of floral resources on pollinator visits to plants varied across scales and depended on the resources provided by individual plants. At large scales (radii $>25 \mathrm{~m}$ around focal plants), high sugar density decreased per-plant visitation rates, i.e. plants competed for animal pollinators. At small scales (radii $<5 \mathrm{~m}$ around focal plants), we observed either competition or facilitation for pollinators between plants, depending on the sugar amount offered by individual focal plants. In plants with copious sugar, per-plant visitation rates increased with increasing local sugar density, but visitation rates decreased in plants with little sugar. Our study underlines the importance of scale-dependent responses of pollinators to floral resources and reveals that pollinators' responses depend on the interplay between individual floral resources and local resource neighbourhood.
\end{abstract}

Since about $90 \%$ of angiosperms are dependent on animal pollination (Ollerton et al. 2011), studies on plant-pollinator interactions are of immense ecological importance (Heithaus 1974, Bond 1994, Dixon 2009, Menz et al. 2011). Floral energy rewards produced by plants play a crucial role in mediating plant-pollinator interactions (Heinrich and Raven 1972, Heinrich 1975) because foraging movements of pollinators are influenced by the spatially heterogeneous distribution of floral resources [Ghazoul 2005, see Carlo and Morales (2008) for a study on seed-dispersal interactions]. Pollinators tend to optimise their foraging movements in order to balance energy intake in relation to energy expenditure and, according to optimal foraging theory (Cody 1989), this may lead to an ideal free distribution of pollinators among resource patches (Fretwell and Lucas 1970).

Pollinator richness and abundance are often positively correlated with the richness and abundance of plant species (Potts et al. 2003, Biesmeijer et al. 2006, Dauber et al.
2010). However, pollinator abundance may not increase proportionally to the resource density provided by a plant community. A decrease in the pollinator to resource ratio may emerge because the size of the pollinator population is constrained by other environmental factors (Donaldson and Nänni 2002, Feldman and McGill 2014) or influenced by competition among pollinators (Ford and Paton 1982, Smith-Ramirez and Armesto 2003, Mac Nally and Timewell 2005). Under such circumstances, the pollination services are shared among more plants within a community (Goulson 2000) and pollinators become more selective in their visits to plants (Schmitt 1983), directing their foraging movements toward resource 'hotspots' within plant communities.

Pollinators mediate pollen transfer between plants and these interactions are crucial for plant reproduction (Ollerton et al. 2011). Thus, the pollinators' response to the resource density of plants may influence the balance between pollinator-mediated facilitation and competition 
between co-flowering plants. An increase in plant density was often associated with a higher frequency of pollinator visits to plants, promoting facilitation of pollination services (reviewed by Ghazoul 2005, see also Essenberg 2012, Duffy et al. 2013). Within sites, however, plants with copious resources might act as 'magnets' for pollinators, concentrating the shared pollination services and inducing competition among plants (Thomson 1981, Ohashi and Yahara 2001, Seifan et al. 2014). Both facilitation and competition for animal pollinators have been observed between co-occurring conspecific and heterospecific plants with shared pollinators. Many studies have reported a positive relationship between plant density and pollinator visitation per unit of time ('per-plant visitation rates' hereafter; Klinkhamer and de Jong 1990, Kunin 1997, Grindeland et al. 2005), while others have found no or negative effects (Aizen 1997, Bosch and Waser 2001, Sieber et al. 2011, Heystek and Pauw 2013). In order to explain these contradictory findings, a recent study underlined the importance of spatial scales (Hegland 2014, see also Rathcke 1983). Hegland (2014) showed that high floral density at small scale $(2.5 \mathrm{~m})$ increased per-plant visitation rates of shared pollinators, but that high floral density at large scale $(25 \mathrm{~m})$ decreased per-plant visitation rates. Thus, facilitation effects of resource abundance on pollinator visits at small scale changed towards competition at large scale. Since plants differ in the amount of provided resources, the effects of neighbourhood resource density on pollinator visits may additionally depend on the resource amount provided by individual plants (Sargent 1990, Ohashi and Yahara 2001, Grindeland et al. 2005). Furthermore, the response of a pollinator to resource density is likely to vary among pollinator species (Essenberg 2013). Functional traits of pollinators, such as body size, may be related to the foraging requirements and the competitive ability of a pollinator species (Parker and Sutherland 1986). We therefore studied how pollinator responses depend on the resource amount of individual plants and how different animal pollinators respond to spatial resource distributions.

Although the importance of energetic rewards in pollination systems has been recognised for decades (Heinrich and Raven 1972, Heinrich 1975), we are aware of only one field study that has attempted to summarize the heterogeneous spatial distribution of floral resources provided by multiple plant species into distribution maps of floral resources (Feldman and McGill 2014). Here we explore how pollinators respond to the distribution of nectar resources provided by plants across scales and discuss how the response may influence the balance between competition and facilitation for animal pollinators between co-occurring plants. We first tested whether the population size of two differently sized nectarivorous birds (Cape sugarbird Promerops cafer and orange-breasted sunbird Anthobaphes violace) were related to variation in resource density among sites. Within sites, we then tested whether per-plant visitation rates were related 1) to bird species identity, 2) avian population size, and 3) the resource amount provided by individual plants and their resource neighbourhood at various spatial extents. Previous studies did not directly quantify the spatial distribution of floral resources, but rather used proxies such as densities of flowering plants (Gunton and Kunin 2009, Hegland 2014). Such approaches, however, neglect variation in individual resource availability, e.g. among plant individuals differing in species identity or size. In this study, we quantified floral resources across various scales using highly resolved spatial distributions of nectar resources provided by species-rich plant communities. The plant communities encompassed 19 species of the genus Protea (family Proteaceae) from South African fynbos. Protea species produce abundant diluted nectar and are regularly visited by nectarivorous birds of the sugarbird (Promeropidae) and sunbird (Nectariniidae) families (Collins and Rebelo 1987).

We used optimal foraging theory to derive our hypotheses (MacArthur and Pianka 1966, Ohashi and Yahara 2001). We predicted A) a linear increase in avian population size with an increasing resource density at a site, but B) a slower increase of the smaller of the two bird species because of inter-specific competition among pollinator species, C) higher per-plant visitation rates on plants with copious nectar than on plants with little nectar; and D) increasing perplant visitation rates at high nectar resource densities at small scale (i.e. facilitation predominant at the small scale), but decreasing per-plant visitation rates at high nectar resource densities at large scale (i.e. competition predominant at the large scale).

\section{Methods}

\section{Study system and study site}

We studied the responses of nectarivorous bird populations and per-plant visitation rates to the spatial distribution of nectar resources of Protea species (family Proteaceae). The genus Protea is emblematic for the ecological diversity found in the fire-prone fynbos biome in the Cape Floristic Region, South Africa (Schurr et al. 2012). In the fynbos biome, Protea species are serotinous, i.e. release seeds after fire. Some Protea species resprout from the roots shortly after fire, while most are killed by fire and seedlings need about three years of growth to produce first flowers (Protea atlas, Rebelo 2001). Flowers are grouped in large inflorescences surrounded by involucral bracts and flowers opens progressively from the outer to the inner circles (Rebelo 2001). Protea species vary greatly in floral traits and attract various flower visitors (Rebelo 2001). In our study, we focused on tall, overstorey Protea species that produce abundant diluted nectar (Collins and Rebelo 1987). Overstorey Protea species are considered to be primarily bird-pollinated (Rebelo 2001). We confirmed this notion for the majority of Protea species with bird-exclusion experiments, although insect pollination also contributed to reproduction of a few Protea species (Schmid et al. 2015). Pollination experiments further showed that all studied overstorey Protea species require animals to set seed, but are self-compatible (Schmid et al. 2015). Nectarivorous bird species visiting Protea species mainly encompass representatives of two families, the sugarbirds (Promeropidae) and sunbirds (Nectariniidae), mostly represented by two species. The large Cape sugarbird (males $36.6 \mathrm{~g}$, females $31.8 \mathrm{~g}$, Tjørve and Scholtz 2007) strongly depends on Protea nectar and its breeding season matches the peak in flowering time of Protea species (Rebelo 1987). The orange-breasted sunbirds (9.5 g, Williams 1993) mostly breed outside the peak flower- 
ing season of Protea species and depend mostly on Ericaceae species, especially during breeding (Rebelo 1987). Cape sugarbirds often chase and dominate the smaller orange-breasted sunbird (Wooller 1982, Rebelo 1987).

Our study was conducted in the winter-rainfall fynbos in the western Cape. The study area $(120 \times 70 \mathrm{~km})$ extended from Bainskloof Pass $\left(33^{\circ} 37^{\prime} \mathrm{S}, 19^{\circ} 05^{\prime} \mathrm{E}\right)$ in the north-west to Gansbaai $\left(34^{\circ} 36^{\prime} \mathrm{S}, 19^{\circ} 30^{\prime} \mathrm{E}\right)$ in the south-east, incorporating variation in elevation from 20-1500 m (Fig. 1A). Field work took place at 27 study sites on which Protea species dominated the overstorey vegetation (so called 'proteoid fynbos'). The study sites varied largely in the number of

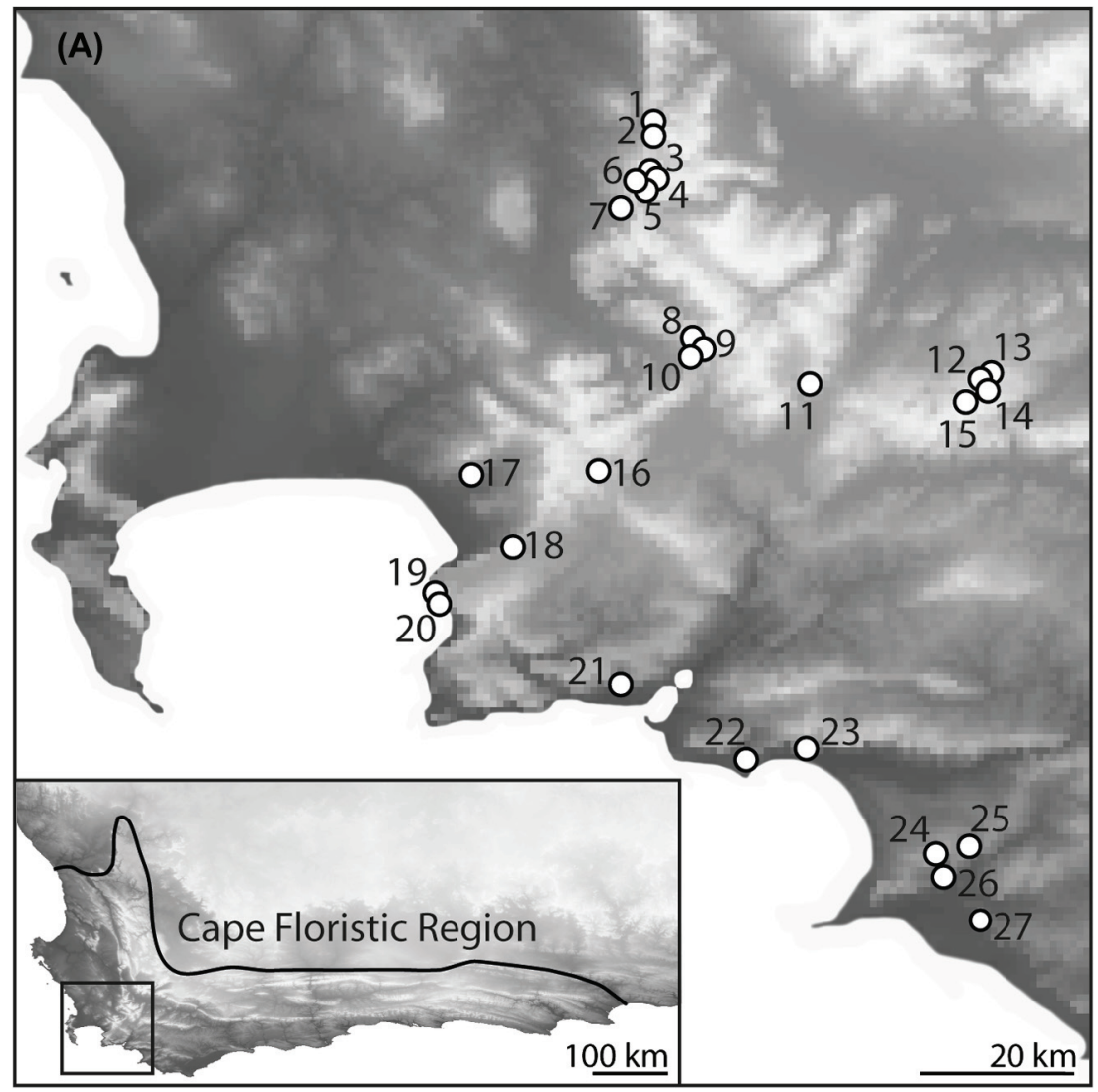

(B)

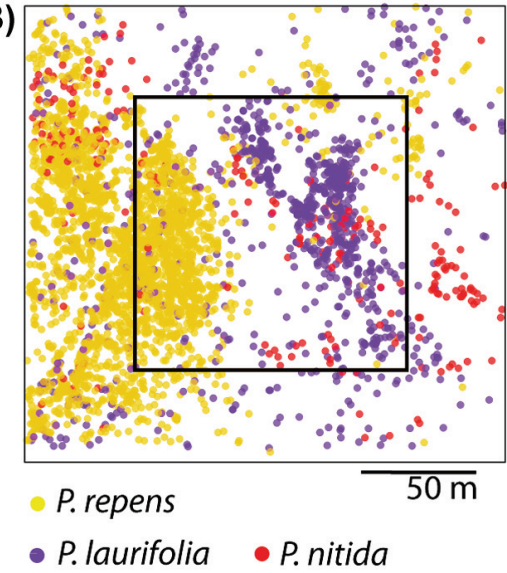

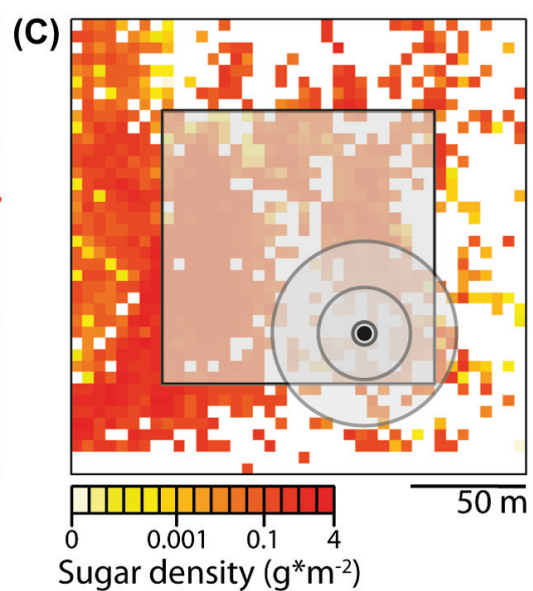

Figure 1. Study area and resource maps of standing crop of nectar sugar in Protea communities. (A) Study area in southern Africa within the Cape Floristic Region (CFR) as delimited by Goldblatt (Goldblatt 1978), black line. 27 study sites (white points) were situated in the south western part of the Fynbos Biome. The image was processed with the elevation grid of 30 arc-seconds $(\sim 1 \mathrm{~km})$ provided by WorldClim (Hijmans et al. 2005). (B) An exemplary $200 \times 200 \mathrm{~m}$ plot (site no. 11) and its $110 \times 110 \mathrm{~m}$ core zone showing the locations of all mapped plants of the three Protea species occurring at this site. (C) Resource map for study site 11 on Julian day 181. Predictions of resource maps were derived by a combination of data from different sources and yielded predictions of the standing crop in nectar sugar for each mapped plant on each day of observation (see Supplementary material Appendix 1, Fig. A1 for analytical details). The grey-shaded areas on top of the resource map illustrate the scale-specific sugar densities: 1) site sugar within the $120 \times 120 \mathrm{~m}$ core zone (grey square) and 2) neighbourhood sugar around a focal plant (black dot) in various concentric radii (grey circles represent exemplary radii at radius 40,20 , and $5 \mathrm{~m}$, respectively). Focal plant sugar (plant scale) was given by the product of the observed number of inflorescences and the estimated standing sugar crop for the species. 
Protea species (2-9 species) and plant density. Adjacent study sites were situated at least $300 \mathrm{~m}$ apart and were unlikely to host the same breeding birds. At each study site, we defined a $200 \times 200 \mathrm{~m}$ plot (including a $120 \times 120 \mathrm{~m}$ core zone). The dimension of the core zone is larger than the mean size of sugarbird territories (mean territory size $=0.8 \mathrm{ha}$, Calf et al. 2003). At each site, we mapped all overstorey Protea plants with a high accuracy Differential Global Positioning System (80-37 300 mapped plants per site). For all mapped plants, we recorded the species identity and the plant size (stem length along the main growth axis). For some large and dense monospecific patches $\left(>10\right.$ plants $\left.\mathrm{m}^{-2}\right)$, plants were not individually mapped. Instead, we mapped the outline of the patch, estimated the plant density in $2 \times 2 \mathrm{~m}$ plots and measured the canopy height of a subsample of 30 plants. We then simulated plant locations in a patch according to a completely random spatial distribution with plant density given by the observed mean density. The sizes of these plants were drawn from a patch-specific gamma distribution estimated by a maximum likelihood fit to the measured plant sizes (the gamma distribution generally fitted better than alternative lognormal or Weibull distributions). Observations of bird activity took place during the flowering peaks of most Protea species from April to August 2012. Every study site was visited three times with two to five weeks between visits. During each visit, we recorded A) population sizes of nectarivorous birds and $\mathrm{B}$ ) the visitation rates of birds on focal plants in the morning hours. For each focal plant, we recorded the exact location and the number of flowering inflorescences in the afternoon following the bird observations.

\section{Resource maps and multiple-scale resource variables}

In order to compare floral resource effects on avian pollinators across various spatial scales, we estimated floral resource distributions at multiple spatial scales, corresponding to site scale, neighbourhood scale and plant scale. The sugar amount of each focal plant (referred to as 'plant sugar') was given by the product of the observed number of inflorescences and the predicted mean sugar amount per inflorescence for each species and site (Supplementary material Appendix 1, Fig. A1). To compute the resource distributions at site and neighbourhood scales, we estimated maps of resource distributions, given by the standing crop of nectar sugar for each mapped plant and for each day of observation (Fig. 1B-C; see details in Supplementary material Appendix 1, Fig. A1). Standing crops of nectar sugar are an accurate measure for nectar availability in Protea species that generally produce very large amounts of nectar that are rarely depleted (Nicolson and Thornburg 2007, Geerts and Pauw 2011).

We used different data sources to estimate standing crops of nectar sugar in time and space. We first collected information on flowering phenology for each Protea species, from the flowering status (binary variable) of 15863 populations (48-4145 per Protea species) provided by the Protea atlas project (Rebelo 2001). We further recorded the number of inflorescences on randomly selected plants $(n=6943$ observations, $51-1245$ per species, $1-865$ per populations) at our study sites between March 2011 and August 2012. For each of these plants, we measured plant size (stem length along the main growth axis), inflorescence length, trunk length and specific leaf area (Supplementary material Appendix 1, Fig. A1). We further used information on sprouting ability of each species, as provided by Rebelo (2001). For a subset of these plant individuals $\left(\mathrm{n}_{\mathrm{tot}}=484\right.$ individuals, 4 80 individual per species, 1-34 individual per population), we also extracted standing crop of nectar from harvested inflorescences $\left(\mathrm{n}_{\mathrm{tot}}=850\right.$ inflorescences $)$ by centrifugation in the field (Armstrong and Paton 1990). We measured nectar volume ( $\mathrm{ml})$ using microsyringes $(0.05 \mathrm{ml}$ precision) and nectar sugar concentration (w/w) using handheld refractometers (Bellingham and Stanley, reading range: 0-50 Brix). The product of nectar sugar concentration (transformed into weight per volume) and nectar volume gave the sugar amount (mg) per inflorescence. For the same plant individuals, we additionally recorded the time of the day and the percentage of open flowers of the harvested inflorescences.

We combined these different sources of information to estimate the spatiotemporal distribution of standing crop of nectar sugar at the study sites for each day of observation ('resource maps', Fig. 1C and Supplementary material Appendix 1, Fig. A1 for analytical details). First, we used the extensive data on the flowering status of Protea populations at different times of the year (from the Protea atlas project, Rebelo 2001) to estimate the phenological peak of flower production for each species ('day of flowering peak'). Second, we described temporal variation in inflorescence number for each sampled plant ('individual plant phenology') using a generalised linear mixed model (GLMM) with Poisson errors. We related the number of inflorescences per plant (response variable) to temporal distance from the flowering peak, plant size, and a set of plant functional traits, while treating site identity and species identity as random effects. Third, we used a linear mixed model to relate the standing crop of nectar sugar per inflorescence ('standing crop of nectar sugar') to plant functional traits, while accounting for time of the day and percentage of open florets in the florescence (as fixed effects), as well as site identity and species identity as random effects. Finally, we used the predictions from the second and third model to estimate the standing crop of nectar sugar for each mapped plant and day of observation, given by the product of the number of inflorescences and standing crop of nectar sugar. This yielded spatially-explicit maps of standing crop of nectar sugar per plant at the days of bird observation ('resource maps'). The spatiotemporal variation in sugar densities depends on Protea densities and its species composition, as well as on the number of inflorescences produced by a Protea individual at a given time. Sugar densities are assumed to be independent from the foraging behaviour of pollinators.

With the estimated resource maps, we were able to calculate 1) site sugar density in the $120 \times 120 \mathrm{~m}$ core zone ('site sugar', expressed as g sugar ha ${ }^{-1}$, Fig. 1C) and 2) neighbourhood sugar density in various radii from focal plants ('neighbourhood sugar', Fig. 1C). Consistent with Hegland (2014), neighbourhood sugar density was calculated across concentric circles of different radii around a focal plant. We considered radii of 1 to $40 \mathrm{~m}$ (Fig. 1C), excluding focal plants from calculations of neighbourhood sugar. The spatial 
variation of site sugar among sites was much larger than temporal variation within sites across the four months of study [Supplementary material Appendix 1, Fig. A2A; between site variation (spatial): sum of squares $=276.1$, within site variation (temporal): sum of squares $=8.0]$. Since the time intervals between repeated visits were similar across all sites (2-5 weeks), the temporal variability in site sugar at each site was not influenced by sampling bias.

\section{Avian populations}

Populations of each nectarivorous bird species were assessed before 10:00 h with $10 \mathrm{~min}$ point counts during three visits at each site. Two observers were situated in the middle of the plot and recorded bird activity in opposite directions. We included all observations of nectarivorous birds within $30 \mathrm{~m}$ distance from the observers to avoid biases in detection probability and used the maximal number of individuals recorded simultaneously to avoid double counts. The nectarivorous bird community in the study area included two families (sunbird family Nectariniidae and sugarbird family Promeropidae) and four other bird species. The number of observations varied strongly between species $(n=493$, orange-breasted sunbird; $n=189$, Cape sugarbird). We did not include the rare observations of the southern doublecollared sunbirds Cinnyris chalybeus and the Malachite sunbirds Nectarinia famosa in population measures because they represented less than $5 \%$ of all observations and were only observed on a few study sites ( $<4$ sites). We observed Cape sugarbirds and orange-breasted sunbirds throughout the study area; population sizes of the two species were unrelated to the elevation of the study sites $\left(R^{2}<0.04 ; \mathrm{p}>0.05\right.$ in both cases). We determined the number of simultaneously observed individuals of Cape sugarbirds and orange-breasted sunbirds separately for each site and visit and derived an overall measure of avian population size by summing the two species-specific estimates, referred to as 'avian population size'. In addition, we recorded whether Cape sugarbirds were breeding at the site at the time of the visits and we estimated the number of defended territories.

\section{Per-plant visitation rates}

During the three visits at each site, we recorded visitation rates of birds on focal plants of 17 Protea species during 45 min sessions from 07:00 to 12:00 h. Depending on the availability of flowering plants, we selected 1-11 focal plants per session, all situated in the core zone of each plot at least $20 \mathrm{~m}$ distant from the observer. We observed 6-346 (median $=46,1333$ in total) focal plants per species across all sites (see Supplementary material Appendix 1, Fig. A2B for the complete species list and sample sizes for each species). We considered only avian visits to focal plants with legitimate foraging events, i.e. birds made contact with the stigma and therefore potentially transferred pollen. Bird visitors frequently foraged on Protea inflorescences from the side ( $17 \%$ of all foraging events observed), and these illegitimate visits were excluded from the analysis. Including all bird visits in the analyses resulted in qualitatively identical results. We used per-plant visitation rates (number of avian visits per unit of time) for each nectarivorous bird species as response variables in further analyses. We only included bird visits from Cape sugarbirds and orange-breasted sunbirds to be consistent with the counts of avian population size, and because the two species represented more than $85 \%$ of all visits.

\section{Data analyses}

We tested the relationships between avian population sizes of the two bird species (Cape sugarbird and orange-breasted sunbird) and main and interaction effects of bird species identity and site sugar (log-transformed) assuming a Poisson error distribution. We also tested the effects of site sugar on the presence or absence of Cape sugarbirds on the study site and the number of territories of Cape sugarbirds on the day of observation, assuming a binomial and a Poisson error distribution, respectively. We included site identity and date as random intercepts in these models.

We tested the relationships between per-plant visitation rate (number of legitimate bird visits per $45 \mathrm{~min}$ ) and bird species identity (Cape sugarbird or orange-breasted sunbird), avian population size (from the point count survey conducted on the same day, but independent from the observation of bird visitation rates), focal plant sugar (log-transformed) and a sugar density variable (log-transformed) assuming a Poisson error distribution. The sugar density was either site sugar or neighbourhood sugar at a specific radius (Fig. 1). Sugar density variables were partly correlated between each other (Supplementary material Appendix 1, Table A1). To account for collinearity, we sequentially tested each sugar density variable, including in the models either site sugar or one of the neighbourhood sugar variables. Because bird species might differ in their response to resources, we also included the two-way interactions of bird species with avian population size, focal plant sugar and the sugar density variable, respectively. Because the effect of sugar density could depend on focal plant sugar, we also added the two-way interaction of focal plant sugar and the respective sugar density variable. In order to account for spatial and temporal autocorrelation between focal plants, we included random intercepts of species identity and, nested in this order, session identity, date and site identity.

All statistical analyses were performed with $\mathrm{R}$ (ver. 3.0.2, $\mathrm{R}$ Core Team). We used mixed effects models as implemented in the 'Ime4' package (ver. 1.0-4, Bates et al. 2013) and model averaging functions as implemented in the 'MuMIn' package (ver. 1.9.5, Barton 2013). For each response variable, model selection among the full model and all possible subsets of predictor variables was performed according to the corrected Akaike information criterion (AICc). We considered all models with $\triangle \mathrm{AICc}<2$ to be similarly supported, best models (Burnham and Anderson 2002). From these subsets of best models, we averaged the parameter estimates across the models where the respective parameter appeared, weighted by the relative importance (given by AICc) of each model (Johnson and Omland 2004). The approach of model averaging allows the quantification of the effect size of each variable across several equivalent models. To assess the significance of the main and interaction effects that 
Table 1. Effects (mean \pm standard errors) of bird species and site sugar on avian population size $(n=84$ point counts for each species). The full model including main and interaction effects of bird species and site sugar was better than all other models $(\triangle \mathrm{AICc}<12$ in comparison to all other models).

\begin{tabular}{lrrr}
\hline & \multicolumn{1}{c}{ Estimates } & $\chi_{\mathrm{DF}=1}^{2}$ & $\mathrm{p}$-value \\
\hline Intercept & $-1.26 \pm 0.24$ & & \\
Bird species (sunbird) & $1.46 \pm 0.25$ & 21.3 & $<0.001$ \\
Site sugar & $1.00 \pm 0.23$ & 7.5 & 0.006 \\
Bird species $\times$ site sugar & $-0.82 \pm 0.23$ & 12.4 & 0.004 \\
\hline
\end{tabular}

were included across all models with $\triangle \mathrm{AICc}<2$, we applied Wald's $\chi^{2}$ tests. The significance level of each variable was tested independently of the sequence of main effects in the statistical model. To ensure comparability among predictor variables, all numerical predictors were scaled and centred prior to analysis.

The data used in this study are archived in the Senckenberg repository: <http://dataportal-senckenberg.de/database/ metacat/bikf.349.1/bikf $>$.

\section{Results}

\section{Avian population size and nectar resources}

Avian population size (i.e. the number of simultaneously observed bird individuals in standardised point counts) increased with site sugar (full model including main and interaction effects of site sugar and bird species: marginal $R^{2}=0.53$, Table 1, Fig. 2 ; $\triangle$ AICc $<12$ to all other models). Populations of orange-breasted sunbird increased continuously with site sugar and were also present at sites with low amounts of site sugar. In contrast, Cape sugarbirds were absent from sites with low amounts of site sugar. Sugarbird populations, however, increased at a higher rate than sunbird populations with increasing site sugar (Table 1, Fig. 2). Accordingly, the presence of breeding sugarbirds and the number of sugarbird territories were positively related to site sugar (presence: $\chi_{\mathrm{DF}=1}^{2}=6.8, \mathrm{p}=0.009$, marginal $R^{2}=0.37$; number of territories: $\chi_{\mathrm{DF}=1}^{2}=13.9, \mathrm{p}<0.001$, marginal $R^{2}=0.34$ ). Avian population size of the two species increased less than proportionally with increasing site sugar. For instance, while about $3000 \mathrm{~g}$ sugar per ha were required for the occurrence of a single Cape sugarbird, about $8000 \mathrm{~g}$ sugar per ha were required for an additional sugarbird individual (model estimates are given in Table 1).

\section{Per-plant visitation rates within communities}

On 1333 focal plants, we recorded a total of 239 visits of Cape sugarbirds and 242 visits of orange-breasted sunbirds. Per-plant visitation rates were positively related to avian population size (Table 2, Fig. 3A). This effect was stronger for sugarbirds than for sunbirds (Table 2), corroborating the stronger increase of sugarbird than sunbird populations with increasing site sugar (Table 1). Per-plant visitation rates were consistently positively correlated with focal plant sugar, i.e. focal plants with copious sugar showed higher per-plant visitation rates than focal plants with little sugar (Table 2, Fig. 3B). Effects of neighbourhood sugar on per-plant visitation rates varied with the radius at which neighbourhood sugar was calculated (Table 2, Fig. 4). At large scales (radii $>25 \mathrm{~m}$ ) and site scale, per-plant visitation rates decreased with sugar density (Table 2, Fig. 3A and Fig. 4) and there was no interaction between focal plant sugar and neighbourhood sugar, i.e. high sugar density at large scales had similarly negative effects on all plants (Table 2, Fig. 4). At small scales (radii $<5 \mathrm{~m}$ ), per-plant visitation rates increased with high sugar density, particularly in plants with copious sugar, but decreased in plants with little sugar (Table 2; Fig. 3B and Fig. 4). Models with neighbourhood sugar measured at 1,2 and $3 \mathrm{~m}$ radii had similarly low AICc values, whereas all models with neighbourhood sugar measured at radii larger than $3 \mathrm{~m}$ showed $\triangle \mathrm{AICc}$ values $>2$ compared to the model with the lowest AICc-value at 2 m-radius.

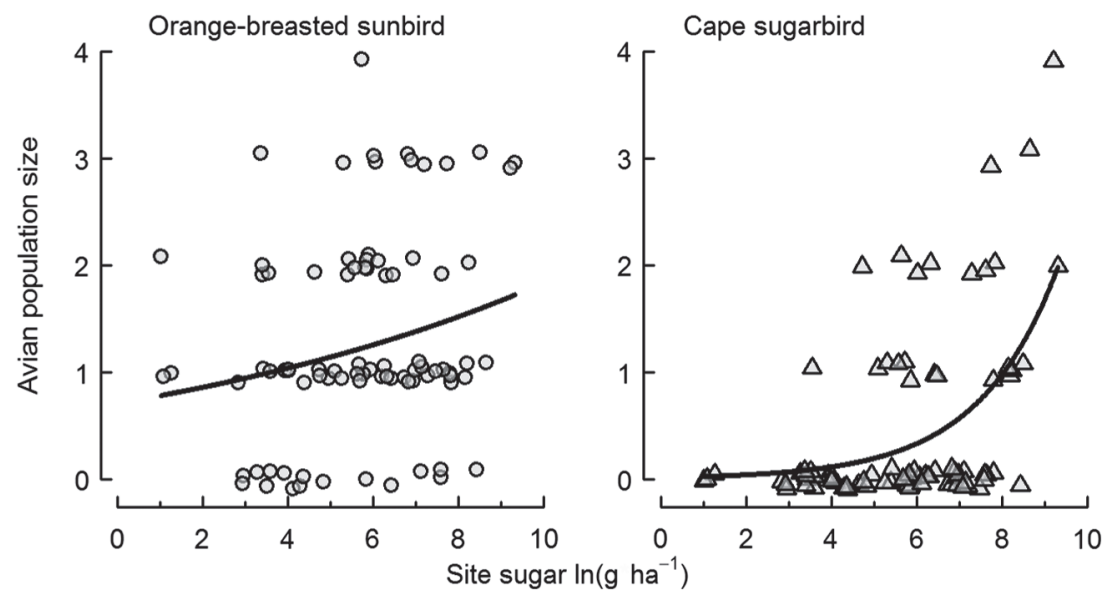

Figure 2. Effect of site sugar (in g sugar ha ${ }^{-1}$, log-normal transformed) on the avian population sizes of the two main nectarivorous bird species present in the study area: orange-breasted sunbirds Anthobaphes violacea (circles) and Cape sugarbirds Promerops cafer (triangles). Raw data (points) for the three visits on the 26 study sites are represented with predicted values of fixed effects (lines). We added jitter to the raw data to reduce overlapping data points. 
Table 2. Effects of bird species, avian population size, focal plant sugar and sugar density on per-plant visitation rates of avian pollinators. We show averaged parameter estimates (mean \pm standard error) across subsets of best models for three models differing in the sugar density variable (log-transformed), while the other variables were identical. We present results for $1 \mathrm{~m}$-neighbourhood sugar (marginal $\left.R^{2}=0.05\right)$, 40 m-neighbourhood sugar (marginal $R^{2}=0.05$ ), and site sugar (marginal $R^{2}=0.08$ ). All numerical predictors were scaled and centred. Significant effects $(p \leq 0.05)$ are written in bold. Asterisks denote the level of significance of the respective predictor term with Wald's $\chi^{2}$-test: * for $\mathrm{p} \leq 0.05$; ** for $\mathrm{p} \leq 0.01$ and $* * *$ for $p \leq 0.001$.

\begin{tabular}{lccc}
\hline & \multicolumn{2}{c}{ Sugar density variables } \\
\cline { 2 - 4 } & $\begin{array}{c}1 \text { m-neighbourhood } \\
\text { sugar }\end{array}$ & $\begin{array}{c}40 \text { m-neighbourhood } \\
\text { sugar }\end{array}$ & $\begin{array}{c}\text { Site } \\
\text { sugar }\end{array}$ \\
\hline Bird species (sunbird) & $0.13 \pm 0.10$ & $0.11 \pm 0.11$ & $0.12 \pm 0.10$ \\
Avian population size & $0.36 \pm 0.18$ & $0.42 \pm 0.18$ & $\mathbf{0 . 6 0} \pm \mathbf{0 . 1 8 * *}$ \\
Focal plant sugar & $\mathbf{0 . 5 1} \pm \mathbf{0 . 1 0 * * *}$ & $\mathbf{0 . 5 0} \pm \mathbf{0 . 1 0 * * *}$ & $\mathbf{0 . 5 0} \pm \mathbf{0 . 1 1} * * *$ \\
Sugar density & $0.06 \pm 0.10$ & $-0.19 \pm 0.15$ & $\mathbf{- 0 . 5 6} \pm \mathbf{0 . 2 1 * *}$ \\
Bird species $\times$ avian population size & $\mathbf{- 0 . 2 8} \pm \mathbf{0 . 1 0 * *}$ & $\mathbf{- 0 . 3 0} \pm \mathbf{0 . 1 1 * *}$ & $\mathbf{- 0 . 3 1} \pm \mathbf{0 . 1 0 * *}$ \\
Bird species $\times$ focal plant sugar & $-0.07 \pm 0.10$ & $-0.12 \pm 0.10$ & $-0.13 \pm 0.10$ \\
Bird species $\times$ sugar density & $-0.18 \pm 0.09$ & $-0.12 \pm 0.09$ & $-0.04 \pm 0.10$ \\
Focal plant sugar $\times$ sugar density & $\mathbf{0 . 2 3} \pm \mathbf{0 . 0 9 *}$ & $0.08 \pm 0.08$ & $0.08 \pm 0.09$ \\
\hline
\end{tabular}

\section{Discussion}

We explore how responses of pollinators to floral resources varied across spatial scales and discuss how this scale-dependence may influence the balance between competition and facilitation for animal pollinators between co-occurring plants. Both Cape sugarbirds and orange-breasted sunbirds responded positively to the amount of sugar resources at the site scale, especially the large-bodied Cape sugarbirds. Within sites, the effects of sugar resources on pollinator visits to plants varied across scales and depended on the individual properties of plants. At large scales (radii $>25 \mathrm{~m}$ and site sugar), high sugar density decreased per-plant visitation rates, i.e. plants competed for animal pollinators. At small scales (radii $<5 \mathrm{~m}$ ), our results suggest that both competition and facilitation for avian pollinators occur between neighbouring plants, depending on the sugar amount offered by the focal plants. At high sugar density, plants with copious sugar attracted more pollinators, whereas plants with little sugar were less frequently visited. Our findings, thus, show that effects of floral resource on plant-pollinator interactions vary across scales and depend on the variability in individual floral resources. This finding has important implications for pollinator effects on plant reproduction.

\section{Avian populations}

In line with our hypothesis, the local abundance of nectar resources strongly influenced the population sizes of the two bird species. Our results suggest a causal link between the density of floral resources and the size of pollinator populations. This may be explained by the high mobility of birds that enables them to track nectar resources over large distances (Fraser 1997a). Consequently, nectarivorous birds aggregate and attempt to breed where nectar resources are abundant (Ford 1979, Calf et al. 2003). Nonetheless, local environmental conditions, for instance those related to elevation and temperature, may also influence the number of nectarivorous birds at a site (Feldman and McGill 2014).
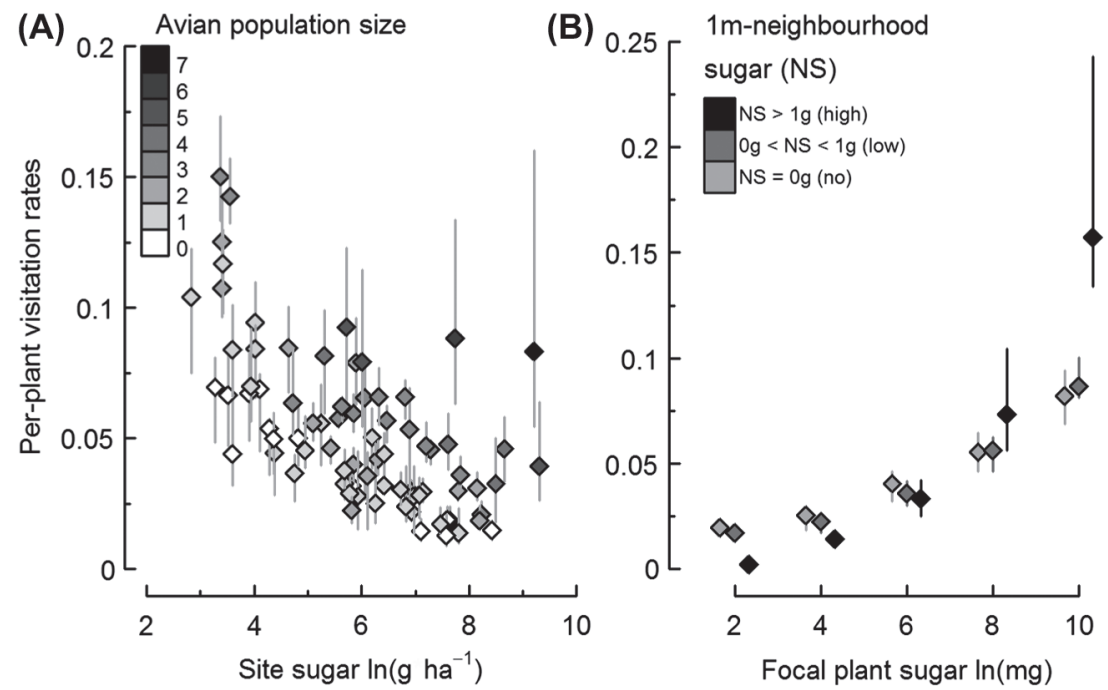

Figure 3. Relationships between per-plant visitation rates and (A) site sugar and avian population size (number of individuals) for every visit per site, and (B) focal plant sugar and $1 \mathrm{~m}$-neighbourhood sugar. We computed the predicted values from the averaged estimates of all fixed effects in the sets of best models with $\triangle \mathrm{AICc}<2$ to draw the medians (points) and 0.05/0.95 quartiles (lines). 


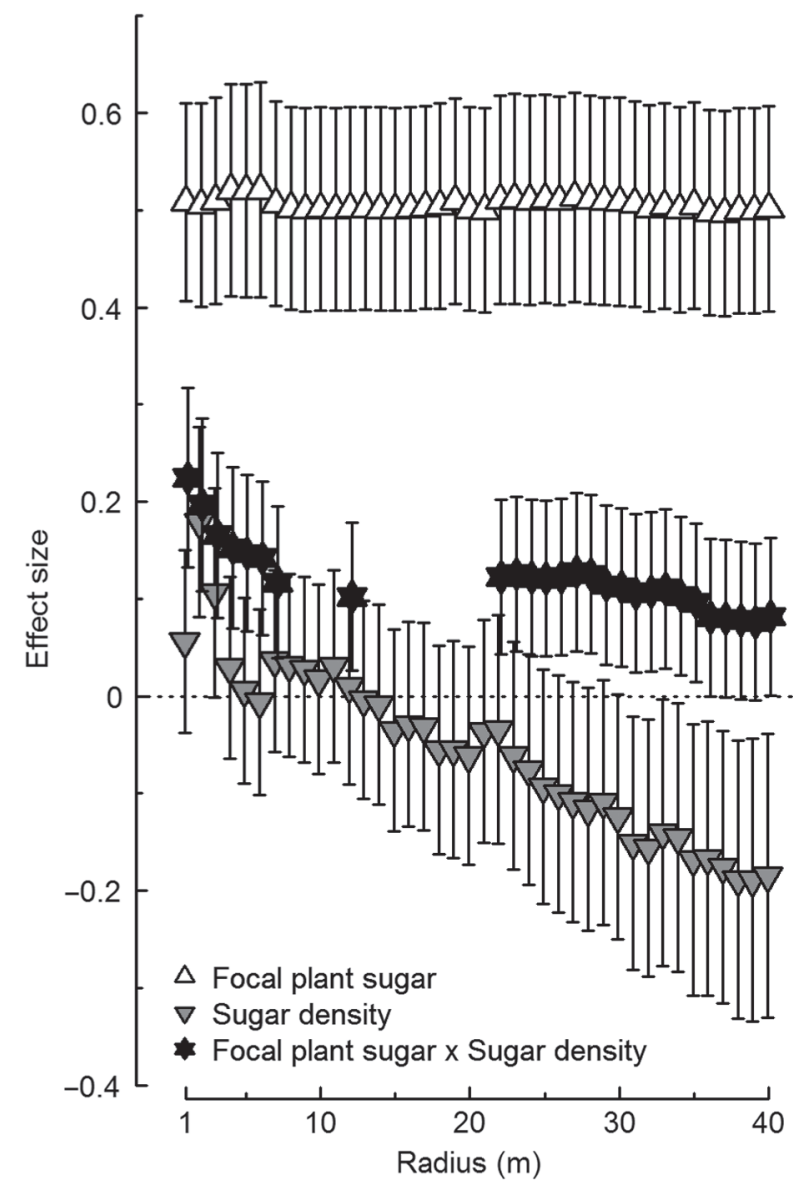

Figure 4. Scale-specific effect sizes of three predictors on per-plant visitation rates: 1) focal plant sugar (unfilled pointing-up triangles), 2) neighbourhood sugar density within various radii from focal plants (grey pointing down triangles) and 3) interaction between focal plant sugar and neighbourhood sugar density (black stars). Focal plant sugar was identical in all models, sugar density values changed according to the radius considered in each model. If the respective main or interaction effects were included in models with $\triangle \mathrm{AICc}<2$, mean averaged estimates were drawn with standard errors, otherwise no effect size was drawn. Table 2 gives effect sizes of all predictors for the radial distances of 1 and $40 \mathrm{~m}$, respectively.

Feldman and McGill (2014) reported only weak relationship between abundance of nectar resources and hummingbird populations. The effect of floral resources on birds may indeed vary among years (Herrera 1998) and bird species (Mulwa et al. 2013).

In our study, bird species differed in their responses to sugar density. The large-bodied Cape sugarbirds were almost always absent from study sites below a threshold sugar density of about $3000 \mathrm{~g}$ sugar ha ${ }^{-1}$. Cape sugarbirds strongly depend on sugar resources of Protea species and their breeding cycle coincides with the flowering peak of Protea species during winter rainfalls (Rebelo 1987, Geerts 2011). Establishing appropriate breeding territories thus requires Cape sugarbirds to track Protea resources over large spatial scales (Fraser 1997a). In contrast, the smaller-bodied orange-breasted sunbirds were commonly observed at low resource density and showed a continuous increase in population size with increasing nectar resources. Even though orange-breasted sunbirds regularly forage on Protea species, their distribution is more closely related to the presence of Ericaceae species, especially during their breeding season (Rebelo 1987), and they are less likely to track Proted resources over large spatial extents (Fraser 1997b). During the austral winter, however, only few Erica species flower and orange-breasted sunbirds therefore frequently forage on Protea species during that time of the year. The distinctive response of the two bird species to sugar density might be further explained by different daily energy requirements related to difference in body mass, given that Cape sugarbirds (males $36.6 \mathrm{~g}$; females 31.8 g; mean $=34.1 \mathrm{~g}$, Tjørve and Scholtz 2007) are substantially heavier than orange-breasted sunbirds $(9.5 \mathrm{~g}$, Williams 1993). Assuming that sugarbirds and sunbirds absorb almost $100 \%$ of the nectar sugar they take up (Lotz and Nicolson 1996, Jackson et al. 1998), the allometric equation for nectarivorous birds (Nagy 2001) predicts daily sugar requirements of about $9.1 \mathrm{~g}$ for Cape sugarbirds and $3.8 \mathrm{~g}$ for orange-breasted sunbirds. Higher flight costs at low resource density and higher daily energy requirements of sugarbirds compared to sunbirds might explain the smaller proportion of sugarbirds compared to sunbirds observed at low resource density (Buchmann et al. 2012).

We observed lower pollinator-to-resource ratios at high sugar density compared to low sugar density. One explanation for the slow increase of avian population size with increasing sugar resources might be competition among avian pollinators (Ford 1979, Mac Nally and Timewell 2005), especially due to the aggressive territorial behaviour of Cape sugarbirds during their breeding season (Wooller 1982, Seiler and Rebelo 1987). The low pollinator-to-resource ratio at high resource density, as observed in this study, lends support to the hypothesis that avian pollinators mediate the negative effect of plant density on Protea seed set at high plant density, as has been reported in previous studies on Protea species (Esler and Cowling 1990, Nottebrock et al. 2013).

\section{Per-plant visitation rates}

Per-plant visitation rates decreased with increasing site sugar, indicating competition between plants for avian pollinators at high sugar density. These results are in line with expected dilution effects of pollinator visits to plants at low pollinatorto-resource ratios (Goulson 2000, Otway et al. 2005). Under this scenario, it has been hypothesised that pollinators concentrate on highly rewarding plants within plant communities (Thomson 1981). Our results corroborate this hypothesis in two ways. First, we observed more frequent bird visits to focal plants with copious sugar. Second, high neighbourhood sugar density at small scales significantly increased the visitation rates of plants with copious sugar, but decreased the visitation rates of plants with little sugar. Plants with little sugar only contribute marginally to the sugar density at small scales and thus become less likely to be visited by pollinators. Plants with copious sugar therefore experienced a competitive advantage over plants with little sugar. Our findings are therefore the first to show that floral resources of focal plants interact with the local resource neighbourhood in their effect on pollinator visitation. The only other study that formally tested the interacting effects between individual properties and local floral neighbourhood on pollinator 
visits found a positive correlation between visitation rates and individual display size and neighbouring floral density (Grindeland et al. 2005). However, this study only detected additive effects of display size and local neighbourhood on visitation rates of pollinators and no synergistic interaction as found in our study.

Increased per-plant visitation rates on plants with copious sugar and the interspecific variation in focal plant sugar among Protea species (Supplementary material Appendix 1, Fig. A2B) may promote interspecific competition for avian pollinators. Interspecific competition for animal pollinators may depend on the local context, since the study sites varied in plant species assembly. That is, a plant species with a medium sugar amount might show competitive advantages in a community where most species produce little sugar, but competitive disadvantages in communities where most plants produce copious sugar. To reduce competition for animal pollinators within plant communities, different nonexclusive mechanisms have been proposed. For instance, competitively inferior species may displace their flowering phenology, thereby avoiding synchronous flowering with highly competitive species (Waser 1978, Silvertown et al. 2005). Additionally, plants may adapt their pollination system and decrease their dependency on the pollinators shared with the competitive plant species (Waser 1983). Hence, variation in flowering phenology among Protea species (Protea atlas, Rebelo 2001) and a low dependency on avian pollination of some Protea species (Coetzee and Giliomee 1985, Schmid et al. 2015) might contribute to reduce interspecific competition for avian pollinators among Protea species.

Per-plant visitation rates generally increased with increasing avian population size. This positive effect was particularly strong for Cape sugarbirds, because they only occurred on the most sugar rich sites, whereas orange-breasted sunbirds were more widespread. At high sugar density, sugarbirds may displace sunbirds towards alternative nectar resources, due to their competitive dominance. Pollination services of orangebreasted sunbirds may nevertheless be important for Protea communities that do not host breeding Cape sugarbirds. At low Protea density, sunbirds may buffer the lack of pollination services provided by sugarbirds. Such buffering effects of displaced pollinators may increase the stability of plant communities (Ghazoul 2006, Verdú and Valiente-Banuet 2008).

\section{Conclusions}

Albeit the prediction of floral resources from species traits is not as accurate as repeated resource measurements on all plant individuals, our approach is more efficient and offers the unique opportunity to estimate the spatial and temporal variability in floral resources among and within plant communities. The consumer-resource relationships detected by our analysis corroborate the strength of this trait-based approach for studying plant-animal interactions in natural communities. Here, we have shown that variation in floral resource availability among sites influences the population density of nectarivorous birds and that within-site variability in floral resources shapes variation in pollinator visitation among plants. The effects of neighbourhood resources on per-plant visitation rates of pollinators varied across scales, suggesting competition between plants for pollinators at large scales and both facilitation and competition at small scales. Furthermore, the interacting effects of individual and neighbourhood resources on visitation rates underline the importance of integrating individual resource variability into resource-based pollination studies. Future studies of resource effects on animal pollinators should therefore account for the scale- and context-dependence of consumer-resource relationships in species-rich communities.

Acknowledgements - We warmly thank L. Ingmann, M. Nowell, B. Olivier, S. Rossow, P. Strauss for their commitment during field work. We are thankful for assistance and advice to P. Barnard, T. Caprano, M. Forrest, S. Gallegos, R. O’Hara, T. Rebelo and M. Templin. We were able to accomplish our study thanks to the friendly collaboration of private land-owners (Floraleae Farm, Paarl; Flower Valley, Gansbaai; Grootbos Nature Reserve, Gansbaai; Heidehof, Gansbaai; Heuningklip Farm, Kleinmond; High Noon Farm, Villiersdorp; G. Moskovitz and S. Moskovitz, DuToitskloof pass) and nature reserve managers and their collaborators (Fernkloof Nature Reserve, Helderberg Nature Reserve, Hottentots-Holland Nature Reserve, Jonaskop Nature Reserve, Limietsberg Nature Reserve, Mont-Rochelle Nature Reserve). We also thank the Frankfurt Cloud for providing the virtual machines on which we ran the statistical models. Field work was conducted under the CapeNature permit AAA005-00213-0028. This work was supported by the German Research Foundation [grant numbers SCHU 2259/3-1, SCHL 1934/1-1] and by the research funding programme 'LOEWE - Landes-Offensive zur Entwicklung Wissenschaftlich-ökonomischer Exzellenz' of Hesse's Ministry of Higher Education, Research, and the Arts.

\section{References}

Aizen, M. A. 1997. Influence of local floral density and sex ratio on pollen receipt and seed output: empirical and experimental results in dichogamous Alstroemeria aurea (Alstroemeriaceae). - Oecologia 111: 404-412.

Armstrong, D. P. and Paton, D. C. 1990. Methods for measuring amounts of energy available from Banksia inflorescences. - Aust. J. Ecol. 15: 291-297.

Barton, K. 2013. MuMIn: multi-model inference. - <https:// cran.r-project.org/web/packages/MuMIn/index.html $>$.

Bates, D. et al. 2013. Ime4: linear mixed-effects models using Eigen and S4. - <https://cran.r-project.org/web/packages/lme4/ index.html $>$.

Biesmeijer, J. C. et al. 2006. Parallel declines in pollinators and insect-pollinated plants in Britain and the Netherlands. - Science 313: 351-354.

Bond, W. J. 1994. Do mutualisms matter? Assessing the impact of pollinator and disperser disruption on plant extinction. - Phil. Trans. R. Soc. B 344: 83-90.

Bosch, M. and Waser, N. M. 2001. Experimental manipulation of plant density and its effect on pollination and reproduction of two confamilial montane herbs. - Oecologia 126: 76-83.

Buchmann, C. M. et al. 2012. Movement upscaled - the importance of individual foraging movement for community response to habitat loss. - Ecography 35: 436-445.

Burnham, K. P. and Anderson, D. R. 2002. Model selection and multimodel inference: a practical information-theoretic approach. - Springer.

Calf, K. et al. 2003. Territoriality of Cape sugarbirds (Promerops cafer) between and within breeding seasons. - Ostrich 74: $125-128$. 
Carlo, T. A. and Morales, J. M. 2008. Inequalities in fruit-remaval and see dispersal: consequences of bird behaviour, neighbourhood density and landscape aggregation. - J. Ecol. 96: 609-618.

Cody, M. L. 1989. Optimization in ecology: natural selection produces optimal results unless constrained by history or by competing goals. - Science 183: 1156-1164.

Coetzee, J. H. and Giliomee, J. H. 1985. Insects in association with the inflorescences of Protea repens (L.) (Proteaceae) and their role in pollination. - J. Entomol. Soc. S. Afr. 48: 303-314.

Collins, B. G. and Rebelo, A. G. 1987. Pollination biology of the Proteaceae in Australia and southern Africa. - Austral Ecol. 12: 387-421.

Dauber, J. et al. 2010. Effects of patch size and density on flower visitation and seed set of wild plants: a pan-European approach. - J. Ecol. 98: 188-196.

Dixon, K. W. 2009. Pollination and restoration. - Science 325: $571-573$.

Donaldson, J. and Nänni, I. 2002. Effects of habitat fragmentation on pollinator diversity and plant reproductive success in renosterveld shrublands of South Africa. - Conserv. Biol. 16: 1267-1276.

Duffy, K. J. et al. 2013. Does the likelihood of an Allee effect on plant fecundity depend on the type of pollinator? - J. Ecol. 101: 953-962.

Esler, K. J. and Cowling, R. M. 1990. Effects of density on the reproductive output of Protea lepidocarpodendron. - S. Afr. J. Bot. 56: 29-33.

Essenberg, C. J. 2012. Explaining variation in the effect of floral density on pollinator visitation. - Am. Nat. 180: 153-166.

Essenberg, C. J. 2013. Scale-dependent shifts in the species composition of flower visitors with changing floral density. - Oecologia 171: 187-196.

Feldman, R. E. and McGill, B. J. 2014. How important is nectar in shaping spatial variation in the abundance of temperate breeding hummingbirds? - J. Biogeogr. 41: 489-500.

Ford, H. A. 1979. Interspecific competition in Australian honeyeaters - depletion of common resources. - Austral Ecol. 4: $145-164$.

Ford, H. A. and Paton, D. C. 1982. Partitioning of nectar sources in an Australian honeyeater community. - Aust. J. Ecol. 7: 6-8.

Fraser, M. W. 1997a. Cape sugarbird. - In: Harrison, J. et al. (eds), The atlas of southern African birds. BirdLife South Africa, pp. 484-485.

Fraser, M. W. 1997b. Orange-breasted sunbird. - In: Harrison, J. et al. (eds), The atlas of southern African birds. BirdLife South Africa, pp. 492-493.

Fretwell, S. D. and Lucas, H. L. 1970. On territorial behaviour and other factors influencing habitat distribution in birds. - Acta Biotheor. 19: 16-36.

Geerts, S. 2011. Assembly and disassembly of bird pollination communities at the Cape of Africa. - PhD thesis, Stellenbosch Univ.

Geerts, S. and Pauw A. 2011. Farming with native bees (Apis mellifera subsp. capensis Esch.) has varied effects on nectarfeeding bird communities in South African fynbos vegetation. - Popul. Ecol. 53: 333-339.

Ghazoul, J. 2005. Pollen and seed dispersal among dispersed plants. - Biol. Rev. Camb. Phil. Soc. 80: 413-443.

Ghazoul, J. 2006. Floral diversity and the facilitation of pollination. - J. Ecol. 94: 295-304.

Goldblatt, P. 1978. An analysis of the flora of southern Africa: its characteristics, relationships, and orgins. - Ann. Missouri Bot. Gard. 65: 369-436.

Goulson, D. 2000. Why do pollinators visit proportionally fewer flowers in large patches? - Oikos 91: 485-492.

Grindeland, J. M. et al. 2005. Effects of floral display size and plant density on pollinator visitation rate in a natural population of Digitalis purpurea. - Funct. Ecol. 19: 383-390.
Gunton, R. M. and Kunin, W. E. 2009. Density-dependence at multiple scales in experimental and natural plant populations. - J. Ecol. 97: 567-580.

Hegland, S. J. 2014. Floral neighbourhood effects on pollination success in red clover are scale-dependent. - Funct. Ecol. 28: 561-568.

Heinrich, B. 1975. Energetics of pollination. - Annu. Rev. Ecol. Syst. 6: 139-170.

Heinrich, B. and Raven, P. H. 1972. Energetics and pollination ecology: the energetics of pollinators may have wide implications in floral biology and communtiy ecology. - Science 176: 597-602.

Heithaus, E. R. 1974. The role of plant-pollinator interactions in determining community structure. - Ann. Missouri Bot. Gard. 61: 675-691.

Herrera, C. M. 1998. Long-term dynamics of mediterranean frugivorousbirds and fleshy fruits: a 12-year study. - Ecol. Monogr. 68: 511-538.

Heystek, A. and Pauw, A. 2013. Does competition for pollinators contribute to structuring Erica communities? - J. Veg. Sci. 25: 648-656.

Hijmans, R. J. et al. 2005. Very high resolution interpolated climate surfaces for global land areas. - Int. J. Climatol. 25: 1965-1978.

Jackson, S. et al. 1998. Apparent absorption efficiencies of nectar sugars in the Cape sugarbird, with a comparison of methods. - Physiol. Zool. 71: 106-115.

Johnson, J. B. and Omland, K. S. 2004. Model selection in ecology and evolution. - Trends Ecol. Evol. 19: 101-108.

Klinkhamer, P. G. L. and de Jong, T. J. 1990. Effects of plant size, plant density and sex differential nectar reward on pollinator visitation in the protandrous Echium vulgare (Boraginaceae). - Oikos 57: 399-405.

Kunin, W. E. 1997. Population size and density effects in pollination: pollinator foraging and plant reproductive success in experimental arrays of Brassica kaber. - J. Ecol. 85: 225-234.

Lotz, C. N. and Nicolson, S. W. 1996. Sugar preferences of a nectarivorus passerine bird, the lesser double-collared sunbird (Nectarinia chalybea). - Funct. Ecol. 10: 360-365.

Mac Nally, R. and Timewell, C. A. R. 2005. Resource availability controls bird-assemblage composition through interspecific aggression. - Auk 122: 1097.

MacArthur, R. H. and Pianka, E. R. 1966. On optimal use of a patchy environment. - Am. Nat. 100: 603-609.

Menz, M. H. M. et al. 2011. Reconnecting plants and pollinators: challenges in the restoration of pollination mutualisms. - Trends Plant Sci. 16: 4-12.

Mulwa, R. K. et al. 2013. Seasonal fluctuations of resource abundance and avian feeding guilds across forest-farmland boundaries in tropical Africa. - Oikos 122: 524-532.

Nagy, K. A. 2001. Food requirements of wild animals: predictive equations for free-living mammals, reptiles, and birds. - Nutr. Abstr. Rev. Ser. B 71: 21R-31R.

Nicolson, S. W. and Thornburg, R. W. 2007. Nectar chemistry. - In: Nicolson, S. W. et al. (eds), Nectaries and nectar. Springer, pp. 215-264.

Nottebrock, H. et al. 2013. Effects of intraspecific and community density on the lifetime fecundity of long-lived shrubs. Perspect. Plant Ecol. Evol. Syst. 15: 150-161.

Ohashi, K. and Yahara, T. 2001. Behavioral responses of pollinators to variation in floral display size and their influences on the evolution of floral traits. - In: Chittka, L. and Thomson, J. D. (eds), Cognitive ecology of pollination. Cambridge Univ. Press, pp. 274-296.

Ollerton, J. et al. 2011. How many flowering plants are pollinated by animals? - Oikos 120: 321-326.

Otway, S. et al. 2005. Resource dilution effects on specialist insect herbivores in a grassland biodiversity experiment. - J. Anim. Ecol. 74: 234-240. 
Parker, G. A. and Sutherland, W. J. 1986. Ideal free distributions when individuals differ in competitive ability: phenotypelimited ideal free models. - Anim. Behav. 34: 1222-1242.

Potts, S. G. et al. 2003. Linking bees and flowers: how do floral communities structure pollinator communities? - Ecology 84 : 2628-2642.

Rathcke, B. 1983. Competition and facilitation among plants for pollination. - In: Real, L. (ed.), Pollination biology. Academic Press, pp. 305-329.

Rebelo, A. G. 1987. Bird pollination in the Cape flora. In: Rebelo, A. G. (ed.), Preliminary synthesis of pollination biology in the Cape flora. CSIR, pp. 83-108.

Rebelo, A. G. 2001. Proteas: a field guide to the Proteas of southern Africa. - Fernwood Press.

Sargent, S. 1990. Neighborhood effects on fruit removal by birds: a field experiment with Viburnum dentatum (Caprifoliaceae). - Ecology 71: 1289-1298.

Schmid, B. et al. 2015. Reward quality predicts effects of bird-pollinators on the reproduction of African Protea shrubs. - Perspect. Plant Ecol. Evol. Syst. 17: 209-217.

Schmitt, J. 1983. Flowering plant density and pollinator visitation in Senecio. - Oecologia 60: 97-102.

Schurr, F. M. et al. 2012. Fynbos Proteaceae as model organisms for biodiversity research and conservation. - S. Afr. J. Sci. 108: 4-7.

Seifan, M. et al. 2014. The outcome of shared pollination services is affected by the density and spatial pattern of an attractive neighbour. - J. Ecol. 102: 953-962.

Seiler, H. W. and Rebelo, A. G. 1987. A sexual difference in the Cape sugarbird's role as pollinator of Protea lepidocarpodendron. - Ostrich 58: 43-45.

Supplementary material (Appendix ECOG-01621 at $<$ www.ecography.org/appendix/ecog-01621>). Appendix 1.
Sieber, Y. et al. 2011. Do alpine plants facilitate each other's pollination? Experiments at a small spatial scale. - Acta Oecol. 37: 369-374.

Silvertown, J. et al. 2005. Reinforcement of reproductive isolation between adjacent populations in the Park Grass Experiment. - Heredity 95: 198-205.

Smith-Ramirez, C. and Armesto, J. J. 2003. Foraging behaviour of bird pollinators on Embothrium coccineum (Proteaceae) trees in forest fragments and pastures in southern Chile. - Austral Ecol. 28: 53-60.

Thomson, J. D. 1981. Spatial and temporal components of resource assessment by flower-feeding insects. - J. Anim. Ecol. 50: 49-59.

Tjørve, K. M. C. and Scholtz, G. 2007. Morphological characteristics of Cape sugarbirds (Promerops cafer) from Helderberg Nature Reserve. - Afr. Zool. 42: 199-203.

Verdú, M. and Valiente-Banuet, A. 2008. The nested assembly of plant facilitation networks prevents species extinctions. - Am. Nat. 172: 751-760.

Waser, N. M. 1978. Competition for hummingbird pollination and sequential flowering in two Colorado wildflowers. - Ecology 59: 934-944.

Waser, N. M. 1983. The adaptive nature of floral traits: ideas and evidence. - In: Real, L. A. (ed.), Pollination biology. Academic Press, pp. 241-285.

Williams, J. B. 1993. Energetics of incubation in free-living orange-breasted sunbirds in South Africa. - Condor 95: $115-126$.

Wooller, R. D. 1982. Feeding interactions between sunbirds and sugarbirds. - Ostrich 53: 114-115. 